\title{
Seroprevalence of Human Fascioliasis Using ELISA in Sistan and Baluchestan Province, Southeast of Iran
}

\author{
Hosnie Hoseini ${ }^{1, *}$ and Soudabeh Etemadi ${ }^{2,3}$ \\ ${ }^{1}$ Department of Laboratory Sciences, Zahedan Branch, Islamic Azad University, Zahedan, Iran \\ ${ }^{2}$ Infectious Diseases and Tropical Medicine Research Center, Resistant Tuberculosis Institute, Zahedan University of Medical Sciences, Zahedan, Iran \\ ${ }^{3}$ Department of Parasitology and Mycology, Faculty of Medicine, Zahedan University of Medical Sciences, Zahedan, Iran \\ "Corresponding author: Department of Laboratory Sciences, Zahedan Branch, Islamic Azad University, Zahedan, Iran. Email: hosniehoseini@gmail.com
}

Received 2020 February 19; Revised 2020 May 05; Accepted 2020 May 15.

\begin{abstract}
Background: Fascioliasis is a zoonotic disease caused by the liver parasites, Fasciola hepatica, and F. gigantica.

Objectives: The aim of this study was to determine the seroprevalence of fascioliasis in Zahedan and the surrounding towns (i.e., Zabol, Chabahar, Iranshahr, etc.) in the Southeast of Iran.

Methods: This cross-sectional study was conducted in 2017. Based on statistical estimations, 251 human serum samples were collected randomly in Zahedan and surrounding towns (Zabol, Chabahar, Iranshahr, and others), then the samples were analyzed using indirect enzyme-linked immunosorbent assay (ELISA) test. A questionnaire was obtained from each individual. Statistical analysis was performed using the chi-square test in SPSS, version 20.

Results: Of the 251 samples, the anti-fasciola antibody was detected in $6(2.40 \%)$ samples. There was a significant relationship between the use of local freshwater vegetables and seropositivity to fasciolosis.

Conclusions: This study showed that the prevalence of human fascioliasis was higher among women (2.70\%) compared to men $(0.0 \%)$, and raising health levels and health education can reduce the prevalence of human fascioliasis disease.
\end{abstract}

Keywords: Seroepidemiology, Fasciola hepatica, ELISA, Southeast of Iran

\section{Background}

Fascioliasis is a zoonotic disease caused by Fasciola hepatica and F. gigantica trematode liver fluke. It is estimated that 17 million people are infected with these parasites, with an additional 91.1 million at risk for this infection (1). In Eastern Europe, South America, and North Africa, F. hepatica is particularly endemic. Turkish studies have reported a prevalence of $0.03 \%-0.8 \%$ for $F$. hepatica infection (2). Children are generally more commonly infected than adults, although infections appear to be more serious in women with higher liver or biliary complications (3). Sheep, goat, cattle and other ruminants are mainly contaminated with trematoda. Transmission to people who are unintended final hosts takes place after the ingestion of contaminated aquatic vegetation such as watercress or metacercariae $(4,5)$. Oviposition occurs within 3 4 months after the initial infection, and adult flukes have a life span of up to 10 years. Clinical presentations typically occur after the parasite remains in the liver (6). While two clinical phases of fascioliasis have been recognized in humans, diagnosis and distinguishing between them is often difficult. The acute phase includes larval migration to the liver and lasts 1 - 3 months after metacercariae ingestion. The chronic phase begins when the adult flukes enter the bile ducts, which can last many years. Nearly half of patients during the chronic period may be asymptomatic (7). Many studies have reported cases of mixed-phase fascioliasis in recent years (8-11). Although fasciolosis is generally considered as a notable veterinary problem, human fasciolosis has recently been regarded as the main health issue in numerous countries $(12,13)$. According to the World Health Organization (WHO) report, Iran has been placed among the six countries recognized to have a serious concern with fasciolosis $(2,14,15)$. Fasciolosis has led to two important epidemics in Iran in 2009 and 2011, respectively, which have been the biggest epidemics of fasciolosis in history $(16,17)$. According to the seroprevalence studies of fasciolosis in Yasouj (2011), Lorestan (2015) and Isfahan (2014), 
in Iran, anti-Fasciola antibodies were positive in 1.8, 0.7 and $1.7 \%$ of the cases, respectively $(9,10,18)$.

Several techniques, including serological and parasitological methods are used for the diagnosis of fasciolosis. Parasitological methods have the highest specificity, but some factors such as low rate of parasite eggs, transient infection, and acute and obstructive infections reduce the sensitivity of these methods. Serological tests are usually used for the recognition of anti-Fasciola antibodies in serum samples in the acute phase and ectopic fasciolosis. These methods are appropriate for diagnosing chronic fasciolosis by identifying specific antigens in stool samples and antibodies in the serum as well (19). Therefore, serological methods such as ELISA are commonly used to diagnose human fasciolosis in Iran (20).

\section{Objectives}

This study aimed to determine the seroprevalence of fascioliasis in Sistan and Baluchestan Province, Southeast of Iran, in 2017.

\section{Methods}

\subsection{The Study Area}

Sistan and Baluchestan Province is located in the Southeast of Iran. The study population consisted of individuals referred to the diagnostic laboratories of Zahedan, Zabol, Chabahar, and Iranshahr. Sampling was performed in the diagnostic laboratories, and 251 human serum samples were collected randomly. Informed consent forms and questionnaires were obtained from the volunteers. The specimens were stored in an ice container during the sampling (Figure 1).

The inclusion criterion was providing consent to participate in this study, and the exclusion criteria were unwillingness to continue participation in the study and having had a positive antibody titer against fasciolosis. Withdrawal of the individuals from the study was one of the limitations of this study. It was also not possible to follow the cases to identify false positives.

\subsection{Serum Samples and Enzyme-Linked Immunosorbent Assay (ELISA)}

Four milliliters of venous blood specimens were obtained from 251 participants. The blood samples were centrifuged $(2500 \mathrm{~g})$ for $10 \mathrm{~min}$ to obtain the serum. The serum was separated from clotted blood and was transferred to a $-20^{\circ} \mathrm{C}$ freezer.

In the next step, serum samples were tested using a 96well ELISA kit (Pishtaz Teb, Iran) specific for Fasciola hepatica. In this technique, microplate wells are coated with a certain amount of Fasciola hepatica-specific antigens.

The samples were diluted 1 to 100 (1/100) with a diluent solution (phosphate buffer solution). Then, $100 \mu \mathrm{L}$ of diluted specimens and the controls were poured into the wells according to the following procedure: the first well was considered as blank, and the reagent was poured into it. Two wells were selected for the positive control (positive pooled sera containing anti-Fasciola hepatica antibodies diluted in a buffer which contained protein as stabilizer and Kathon CG as preservative), and one well was considered for negative control (negative pooled sera in buffer containing protein as a stabilizer and Kathon CG as preservative). The rest of the wells were used for the samples. After pouring the serum, the wells were covered with a special glue and incubated for 30 minutes at room temperature. Subsequently, the contents of the wells were discarded and washed three times with a prepared wash solution (contained phosphate buffer solution with $0.05 \%$ TWEEN 20 as detergent, $\mathrm{pH}=6$ ). Afterward, $100 \mu \mathrm{L}$ of the conjugated solution (contained polyclonal anti-human IgG labeled with HRP) was poured into the wells and covered with glue. The samples were incubated for 30 minutes. The contents of the wells were discarded and washed three times with wash solution. Subsequently,100 $\mu \mathrm{L}$ of dye solution (contained tetramethylbenzidine and hydrogen peroxide) was added to each well, and the samples were incubated for 15 minutes at room temperature and in the dark. The enzymatic reaction was stopped by adding $100 \mu \mathrm{L}$ of the stopping solution (contained $1 \mathrm{M}$ hydrochloric acid, $\mathrm{pH}<1$ ) to each well. To measure the optical absorption of each well, a microplate reader for ELISA (BioTek Instruments) with a 450-nm filter was used, and optical absorption of all the wells was read out against the Blank. After obtaining adsorption, we started the main stages of the sample test. For this purpose, we needed to obtain the F value, which is used to calculate the cut-off point. The cut-off was calculated as $0.25+\mathrm{X}$ (mean optical absorption of the 9negative controls).

The cut-off was calculated for each microplate. The cut off value of each plate was different, and if the absorbance of a microplate vial was lower than the cut-off point, the result was considered to be negative, and if it was equal or higher, it was considered to be positive. 


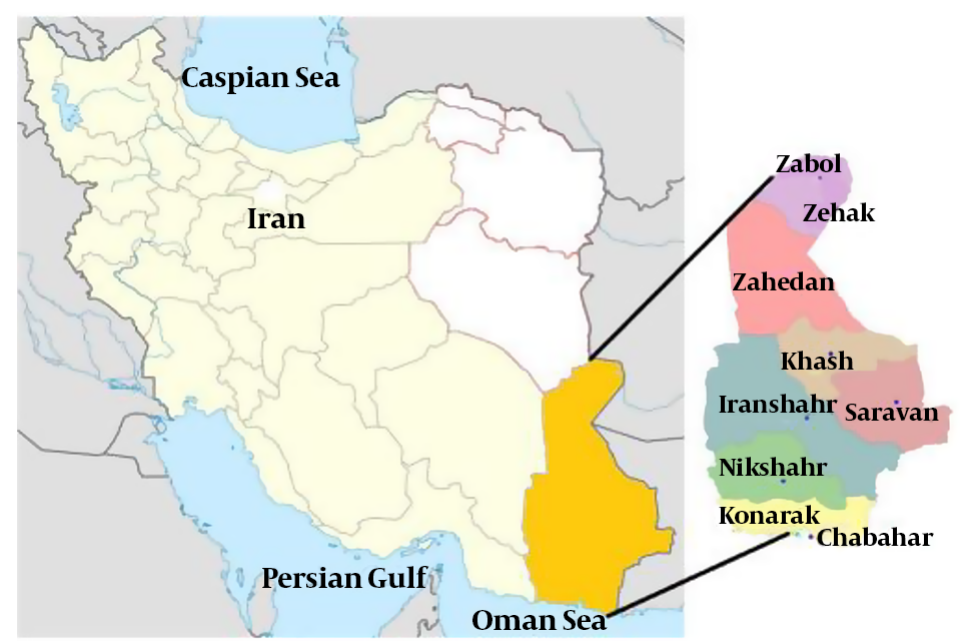

Figure 1. Location of sampling zones (Statistical Center of Iran, www.amar.org.ir)

\subsection{Statistical Analysis}

Statistical analysis was done using SPSS version 20 (Chicago, IL, USA). A Chi-square test was used for analyzing the data. P value of less than 0.05 was considered significant in all the tests.

\section{Results}

Using the ELISA method, 251 individuals were sampled; women had the highest infection prevalence (2.70\%). The highest rate of infection was in the 20 - 39 years old age group (3.30\%), and the lowest rate of infection was observed in those aged 60 - 79 years and over (0\%). No significant correlation was observed between the infection and the age of the patients. However, a significant correlation was found between the infection and the use of local freshwater vegetables $(\mathrm{P}<0.05$; Table 1$)$. The cut-off point was calculated as 0.389 in this study.

\section{Discussion}

In recent years, cases of fascioliasis in many countries and a shift in disease outlook have been reported steadily (21-23). Studies of fascioliasis in endemic areas around the world have reported a very low prevalence $(<1 \%)$ in Basse Normandie and Corsica in France, moderate prevalence (1\% - 10\%) in Porto in Portugal, Alexandria, Nile Delta, and Sharkia in Egypt, while Corazal in Puerto Rico and Cajamarca in Peru have been found to have a high prevalence
$(>10 \%)$. In three studies performed in Van Province, F. hepatica eggs were detected in 5 (2.4\%) of the 206 people in the town of Ercis, in $2(0.68 \%)$ of the 293 students in the $7-15$ age group, and in 1 (0.03\%) of the 3,534 people aged 14 years and above in Van City (11, 22-25).

Sarkari et al. (18) reported a 1.8\% prevalence of fascioliasis in Yasuj, Guilan, and Northern Iran. On the other hand, a small outbreak was reported in Kermanshah, Western Iran $(10,18,26)$. Espinoza et al. (9) reported the prevalence rate of fascioliasis to be $1.7 \%$ in urban and rural areas.

Of course, the positive cases of fascioliasis in this study were higher than those of similar studies, and this may have been due to the use of low sensitivity and specificity commercial kits. In the present study, the total prevalence of human fascioliasis infection was estimated to be $2.40 \%$ in the province of Sistan and Baluchestan. We found statistically significant differences between the two sexes regarding infection rates. Findings showed that the rate of infection was higher among women. No significant correlation was observed between the infection prevalence and age of the patients $(\mathrm{P}>0.05)$.

The highest infection rate was found in the 20 - 39 years old age group (3.30\%), and the lowest rate of infection was reported in those aged 60 - 79 years old and above ( $0 \%$ ). The higher rate of fascioliasis in females than in males can be attributed to the fact that women consume green aquatic plants more often than men do. The higher rate of infection in people aged 20 - 39 years may reflect the increased possibility of encountering the parasite with aging. The higher infection rates among the 20 - 39 years old 


\begin{tabular}{|c|c|c|c|}
\hline Variable & Number of Samples & Frequency of Anti-Fasciola Antibodies & PValue \\
\hline Gender & & & 1.000 \\
\hline Male & 28 & $0(0)$ & \\
\hline Female & 223 & $6(2.70)$ & \\
\hline $0-19$ & 50 & $1(2)$ & \\
\hline $20-39$ & 121 & $4(3.30)$ & \\
\hline $40-59$ & 67 & $1(1.50)$ & \\
\hline $60-79$ & 12 & $0(0)$ & \\
\hline$>80$ & 1 & $0(0)$ & \\
\hline Location of residence & & & 0.523 \\
\hline Zahedan & 231 & $6(2.60)$ & \\
\hline Zabol & 15 & $0(0)$ & \\
\hline Chabahar & 2 & $0(0)$ & \\
\hline Iranshahr & 3 & $0(0)$ & \\
\hline Use of local freshwater vegetables & & & 0.012 \\
\hline Yes & 121 & $6(2.95)$ & \\
\hline No & 130 & $0(0)$ & \\
\hline
\end{tabular}

${ }^{\mathrm{a}}$ Values are expressed as No. (\%).

age group in the present study compared to other studies maybe due to the fact that in this region (Sistan and Baluchestan Province), people in this age group are more likely to be in contact with the contaminated environment.

\subsection{Conclusions}

The results of the present study indicated that fascioliasis is native to the Zahedan Region. Regarding the hygienic issues and health implications, as well as the economic impacts, the burden of this infection in the region is significant; therefore, it is recommended that the following issues be taken into consideration by the researchers and executive authorities of the region: (1) to conduct more extensive studies in the area using serologic tests such as ELISA and to use ultrasound screening; (2) to investigate the possible infection of the intermediate and final hosts in the region; (3) to conduct interventional studies in order to control the spread of the disease in the area; 4 ) to review and estimate the burden of the disease imposed on the people of the region; (5) to educate the people of the region about the ways the infection spreads and to increase their understanding of the disease and its prevention methods and to train them on how to wash vegetables and how to clean a slaughterhouse; and (6) to help the patients with their treatment and grant financial support and to expand social security for the people of this region.

\section{Acknowledgments}

The authors express their gratitude to all those who have directly or indirectly contributed to this project.

\section{Footnotes}

Authors' Contribution: Study concept and design: $\mathrm{HH}$. Acquisition of data: $\mathrm{HH}$ and SE. Analysis and interpretation: SE.

Clinical Trial Registration Code: The clinical registration code was IRCT20140517155180N1.

Conflict of Interests: The authors and coauthors declare that they have no conflict of interest that affects this study. Ethical Approval: The study protocol was approved by the Ethics Committee of Islamic Azad University of Zahedan Branch (code: AE-MLS-WI-321-54).

Funding/Support: This research received financial support from the Islamic Azad University of Zahedan (grant no: 5/5180). 
Informed Consent: A code was assigned for each of the patients and the data were kept totally confidential. The authors wish to thank the personnel of Ali ibn Abi Talib Hospital in Zahedan for their cooperation in this study.

\section{References}

1. Keiser J, Utzinger J. Emerging foodborne trematodiasis. Emerg Infect Dis. 2005;11(10):1507-14. doi: 10.3201/eid1110.050614. [PubMed: 16318688]. [PubMed Central: PMC3366753].

2. Mas-Coma S. Epidemiology of fascioliasis in human endemic areas. J Helminthol. 2005;79(3):207-16. doi: 10.1079/joh2005296. [PubMed: 16153314].

3. Marcos LA, Terashima A, Leguia G, Canales M, Espinoza JR, Gotuzzo E. [Fasciola hepatica infection in Peru: An emergent disease]. Rev Gastroenterol Peru. 2007;27(4):389-96. Spanish. [PubMed:18183272].

4. World Health Organization. Investing to overcome the global impact of neglected tropical diseases: Third WHO report on neglected tropical diseases 2015. Geneva: WHO; 2015.

5. Ozturhan H, Emekdas G, Sezgin O, Korkmaz M, Altintas E. Seroepidemiology of Fasciola Hepatica in Mersin province and surrounding towns and the role of family history of the Fascioliasis in the transmission of the parasite. Turk J Gastroenterol. 2009;20(3):198-203. doi 10.4318/tjg.2009.0007. [PubMed: 19821202].

6. Marcos L, Maco V, Samalvides F, Terashima A, Espinoza JR, Gotuzzo E. Risk factors for Fasciola hepatica infection in children: A casecontrol study. Trans R Soc Trop Med Hyg. 2006;100(2):158-66. doi 10.1016/j.trstmh.2005.05.016. [PubMed:16181652].

7. Jensenius M, Flaegstad T, Stenstad T, Gjolberg T, Vlatkovic L, SchjothIversen L, et al. Fascioliasis imported to Norway. Scand J Infect Dis. 2005;37(6-7):534-7. doi: 10.1080/00365540510034518. [PubMed: 16012024].

8. Sripa B, Kaewkes S, Intapan PM, Maleewong W, Brindley PJ. Foodborne trematodiases in Southeast Asia epidemiology, pathology, clinical manifestation and control. Adv Parasitol. 2010;72:305-50. doi: 10.1016/S0065-308X(10)72011-X. [PubMed: 20624536].

9. Espinoza JR, Timoteo O, Herrera-Velit P. Fas2-ELISA in the detection of human infection by Fasciola hepatica.J Helminthol. 2005;79(3):23540. doi: 10.1079/joh2005303. [PubMed: 16153317].

10. Hatami H, Asmar M, Masoud J, Mansouri F, Namdaritabar H, Ramazankhani A. The first epidemic and new-emerging human Fascioliasis in Kermanshah (Western Iran) and a ten-year follow up, 19982008. Int J Prev Med. 2012;3(4):266-72. [PubMed: 22624083]. [PubMed Central: PMC3354396].

11. Mas-Coma MS, Esteban JG, Bargues MD. Epidemiology of human fascioliasis: A review and proposed new classification. Bull World Health Organ. 1999;77(4):340-6. [PubMed: 10327713]. [PubMed Central: PMC2557647].

12. Arjona R, Riancho JA, Aguado JM, Salesa R, Gonzalez-Macias J. Fascioliasis in developed countries: A review of classic and aberrant forms of the disease. Medicine (Baltimore). 1995;74(1):13-23. doi: 10.1097/00005792-199501000-00002. [PubMed: 7837967].
13. Graham CS, Brodie SB, Weller PF. Imported Fasciola hepatica infection in the United States and treatment with triclabendazole. Clin Infect Dis. 2001;33(1):1-5. doi: 10.1097/00005792-199501000-00002. [PubMed: 7837967].

14. Marcos L, Maco V, Terashima A, Samalvides F, Espinoza JR, Gotuzzo E. Fascioliasis in relatives of patients with Fasciola hepatica infection in Peru. Rev Inst Med Trop Sao Paulo. 2005;47(4):219-22. doi: 10.1590/s0036-46652005000400008. [PubMed: 16138205].

15. Aroonroch R, Worawichawong S, Nitiyanant P, Kanchanapitak A, Bunyaratvej S. Hepatic fascioliasis due to Fasciola hepatica: A two-case report. J Med Assoc Thai. 2006;89(10):1770-4. [PubMed: 17128857].

16. Xuan le T, Hung NT, Waikagul J. Cutaneous fascioliasis: A case report in Vietnam. Am J Trop Med Hyg. 2005;72(5):508-9. [PubMed: 15891121].

17. Abdi J, Naserifar R, Rostami Nejad M, Mansouri V. New features of fascioliasis in human and animal infections in Ilam province, Western Iran. Gastroenterol Hepatol Bed Bench. 2013;6(3):152-5. [PubMed: 24834263]. [PubMed Central: PMC4017511].

18. Sarkari B, Ghobakhloo N, Moshfea A, Eilami O. Seroprevalence of human fasciolosis in a new-emerging focus of fasciolosis in yasuj district, southwest of iran. Iran J Parasitol. 2012;7(2):15-20. [PubMed: 23109941]. [PubMed Central: PMC3469183].

19. Rokni M, Aryaeipour M, Koosha S, Rahimi M. Evaluation of the stability of coated plates with antigen at different temperatures and times by ELISA test to diagnose fasciolosis. Iran J Parasitol. 2010;5(1):416. [PubMed: 22347234]. [PubMed Central: PMC3279827].

20. Rokni MB, Massoud J, O’Neill SM, Parkinson M, Dalton JP. Diagnosis of human fasciolosis in the Gilan province of Northern Iran: Application of cathepsin L-ELISA. Diagn Microbiol Infect Dis. 2002;44(2):175-9. doi: 10.1016/s0732-8893(02)00431-5. [PubMed: 12458125].

21. Motazedian MH, Najjari M, Ebrahimipour M, Asgari Q, Mojtabavi S, Mansouri M. Prevalence of Intestinal parasites among Food-handlers in Shiraz, Iran. Iran J Parasitol. 2015;10(4):652-7. [PubMed: 26811734]. [PubMed Central: PMC4724844].

22. Esteban JG, Flores A, Aguirre C, Strauss W, Angles R, Mas-Coma S. Presence of very high prevalence and intensity of infection with Fasciola hepatica among Aymara children from the Northern Bolivian Altiplano. Acta Trop. 1997;66(1):1-14. doi: 10.1016/s0001-706x(97)00669-4. [PubMed: 9177091].

23. Esteban JG, Gonzalez C, Bargues MD, Angles R, Sanchez C, Naquira C, et al. High fascioliasis infection in children linked to a man-made irrigation zone in Peru. Trop Med Int Health. 2002;7(4):339-48. doi: 10.1046/j.1365-3156.2002.00870.x. [PubMed: 11952950].

24. Nyindo M, Lukambagire AH. Fascioliasis: An ongoing zoonotic trematode infection. Biomed Res Int. 2015;2015:786195. doi: 10.1155/2015/786195. [PubMed: 26417603]. [PubMed Central: PMC4568335].

25. Mercan S, Altunay IK, Taskintuna N, Ogutcen O, Kayaoglu S. Atypical antipsychotic drugs in the treatment of delusional parasitosis. Int J Psychiatry Med. 2007;37(1):29-37. doi: 10.2190/M8M5-H1G2-1257-2017. [PubMed: 17645196].

26. Ashrafi K, Saadat F, O’Neill S, Rahmati B, Amin Tahmasbi H, Pius Dalton J, et al. The endemicity of human fascioliasis in Guilan Province, Northern Iran: The baseline for implementation of control strategies. Iran J Public Health. 2015;44(4):501-11. [PubMed: 26056669]. [PubMed Central: PMC4441963]. 